\title{
Ensaio
}

\section{Relações bilaterais Brasil-EUA: \\ o reaquecimento das relações como oportunidade de barganha a uma reforma do Conselho de Segurança da ONU*}

\section{Brazil-US bilateral relations: the reheat of relations as a bargain opportunity to a reform of the UN Security Council}

Luis Filipe de Souza Porto ${ }^{1}$ Thauan Santos ${ }^{2}$
* Recebido em: 22/04/2015. Aprovado em: 14/05/2015.

1 Graduando em Defesa e Gestão Estratégica Internacional pela Universidade Federal do Rio de Janeiro (DGEI/UFRJ). E-mail: filipeporto@ icloud.com.

2 Mestre em Relações Internacionais pelo Instituto de Relações Internacionais da Pontifícia Universidade Católica do Rio de Janeiro (IRI/ PUC-Rio) e professor da mesma instituição, e professor do DGEI/UFRJ. E-mail: santos. thauan@gmail.com.

\section{Resumo}

O presente artigo procura analisar, através da ferramenta metodológica mais conhecida por "Análise de Discurso", os desdobramentos do episódio de espionagem pela Agência Nacional de Segurança Americana (NSA), bem como propor um questionamento sobre os arranjos geopolíticos que o Brasil, como Estado autônomo, pode seguir. Em seguida, buscaremos abordar a reaproximação de Obama e Dilma na recente VII Cúpula das Américas, onde ambos planejaram uma visita de trabalho pela presidente brasileira a Washington em Junho de 2015. Tal consenso poderia ser entendido como um fim das tensões diplomáticas entre os dois Estados. No encontro serão abordados diversos temas da agenda bilateral do Brasil com os Estados Unidos, mas será que o mesmo poderá se configurar como uma oportunidade de barganha por - parte do Brasil - no que se refere à campanha brasileira pela reforma do Conselho de Segurança da ONU?

Palavras-chave: Análise de discurso. Relações bilaterais Brasil-EUA. Política externa brasileira. Conselho de Segurança.

\begin{abstract}
The present paper aims to analyze, through a methodological tool better known as Discourse Analysis, the outspreads of the NSA's spying episode revealed by Edward Snowden, as well as propose a questioning on the geopolitical arrangements that Brazil, as an independent and autonomous state, may choose to follow. Thereafter, this paper will seek to address the rapprochement of presidents Obama and Rousseff in the recent VII Summit of the Americas, where both planned a working visit by the Brazilian president to Washington in June, 2015. This agreement can be understood as an end to the diplomatic tensions between the two states. The meeting will address a variety of issues that compose the bilateral agenda between the two states, but can it configure as an opportunity of Brazil to bargain a support from Washington to its reform of the Security Council's campaign?
\end{abstract}

Keywords: Discourse analysis. Brazil-US bilateral relations. Brazilian foreign policy. UN Security Council. 


\section{Introdução}

Veremos ao longo deste artigo, dividido em 4 seções, a oportunidade que o Brasil tem de barganhar apoio à campanha por um assento permanente no Conselho de Segurança da ONU através da reaquecimento das relações bilaterais com os Estados Unidos, que haviam sido abaladas pelo episódio da espionagem americana.

Na seção 1, apresentaremos a metodologia que propiciou a formulação deste artigo, uma ferramenta chamada "Análise de Discurso". Em seguida, veremos na seção 2 os desdobramentos do episódio da espionagem americana, colocando em voga os discursos e posicionamentos de chefes de Estado, presidentes, ministros e outras figuras de governo.

Logo, na seção 3, veremos a bifurcação geopolítica que o Brasil está submetido e as consequências de escolher entre um caminho ou outro. Já na seção 4 , abordaremos a reaproximação do Brasil com os Estados Unidos na VII Cúpula das Américas e como isso pode se configurar de fato como uma oportunidade de barganha à Washington no tocante a campanha brasileira por um assento de segurança no Conselho de Segurança. Fim, apresentamos alguma considerações finais, bem como a bibliografia utilizada no estudo.

\section{Análise de discurso e o poder das palavras}

No presente artigo, abordamos como o reaquecimento das relações bilaterais do Brasil com os Estados Unidos pode se configurar como uma oportunidade de barganha por parte do Brasil quanto ao apoio de Washington à campanha brasileira pela reforma do Conselho de Segurança da ONU através de uma ferramenta metodológica conhecida como "Análise de Discurso" (NEUMANN, 2008; HANSEN, 2006).

Esta ferramenta provém da teoria pós-estruturalista das relações internacionais e, de acordo, com Hansen (2006, p. 1) "poststructuralist discourse analysis can create a theoretically vibrant and rigorous research agenda that speaks to pertinent political issues ${ }^{1}$.

Ainda de acordo com Hansen (2006, p. 1):

It is a research agenda which engages classical questions of foreign policy-how do states generate responses to the problems they face and
A Análise de discurso pós-estruturalista pode realmente criar uma agenda de pesquisa teoricamente vibrante e rigorosa pertinente às questões políticas. how do politicians rally support for their calls for action? - as well as bridges to the importance of media and political opposition for how political debates unfold ${ }^{2}$.

Por outro lado, de acordo com Neumann (2008, p. 63):

Discourse analysis may start with a specific outcome and demonstrate the preconditions for it happening, demonstrating concurrently that the outcome might have been different. To map these patterns in representations, discourse analysts examine utterances. They may be texts (written statements that do some kind of work in a context). ${ }^{3}$

O caráter descritivo que apresenta o artigo representa um instrumento desta ferramenta metodológica. Nesse sentido,

The more such things may be specified empirically, the better the analysis. The ideal is to include as many representations and their variations as possible, and to specify where they are to be found in as high a degree as possible. Methodologically, discourse analysis points to the importance of being explicit about your sweep: the broader it is, the more general knowledge you need, and the less risky it is to leave lacunae ${ }^{4}$ (NEUMANN, 2008, p. 62-65).

A metodologia utilizada na análise de discurso propõe a leitura de textos como imprescindível, bem como a definição dos tipos de textos que serão utilizados para a leitura de acordo com o escopo da abordagem. Neste artigo, os tipos de textos utilizados foram artigos em jornais, que demonstram as opiniões de especialistas que divergem quanto à posição que o Brasil deve seguir geopoliticamente e suas consequências. Além disso, fo-

2 É uma agenda de pesquisa que envolve questões clássicas da política externa - como os Estados geram respostas para os problemas que enfrentam e como os políticos reúnem apoio para as suas ações? - Bem como estabelece a importância da mídia e da oposição política para saber como debates políticos se desdobram

3 A análise de discurso pode começar com um objetivo específico e demonstrar as pré-condições para que isso aconteça, demonstrando, ao mesmo tempo, que o resultado poderia ter sido diferente. Para mapear esses padrões em representações, analistas de discurso examinam afirmações. Essas afirmações podem ser textos (declarações escritas ou faladas que funcionam em algum contexto).

4 Quanto mais as ideias puderem ser especificadas empiricamente, melhor a análise. O ideal é incluir o maior número possível de representações e suas variações e especificar onde elas podem ser encontradas em um grau tão elevado quanto possível. Metodologicamente, a Análise de Discurso aponta para a importância de ser explícito sobre a investigação: quão mais ampla é, maior o grau de conhecimento geral necessário e menor será o risco de deixar brechas. 
ram utilizadas resoluções e discursos da Assembleia Geral da ONU e de outros organismos multilaterais, como o Mercosul, que demonstram a posição de chefes de Estado e ministros frente ao episódio da espionagem americana. Ainda, de acordo com Neumann, "some texts will show up as crossroads or anchor points, such as short government treatises outlining policy. These are called canonical texts or monuments" (NEUMANN, 2008, p. 67).

\section{Os desdobramentos do episódio de espio- nagem pela Agência Nacional de Segurança Americana (NSA)}

As denúncias sobre a espionagem e mecanismos de vigilância global que foram reveladas por Edward Snowden, em 2013, tiveram enorme abalo nas relações bilaterais do Brasil e dos Estados Unidos, bem como de outros diversos países. "Vários países foram alvos, gerando tensões diplomáticas e preocupações em relação à segurança da internet em todo o mundo." (SOARES, 2013, p. 1).

Nesse contexto, e, em discurso na $68^{\mathrm{a}}$ Assembleia Geral da ONU, a presidente do Brasil, Dilma Rousseff, afirmou que "Estamos diante de um caso grave de violação dos direitos humanos e das liberdades civis, da invasão e captura de informações sigilosas relativas às atividades empresariais, e, sobretudo de desrespeito à soberania nacional do meu país" (ROUSSEFF, 2013a). Tal discurso, apesar de atribuir à ONU o papel de liderança no esforço de regular o comportamento dos Estados frente a essas tecnologias, foi uma oportunidade de o Brasil abraçar a questão e protagonizar articulações nesse sentido, tanto no âmbito interno, com a aprovação do Marco Civil da Internet, como no âmbito internacional, com o adiamento de sua visita a Washington, decisão que gerou constrangimentos diplomáticos e consequências às relações bilaterais entre os EUA e o Brasil.

Por sua vez, o atual embaixador da Missão do Brasil junto à ONU em Nova Iorque, que era então Ministro das Relações Exteriores do Brasil durante o episódio, Antonio Patriota, indagou, em conversa com o secretário de Estado John Kerry, de visita ao Brasil em 2013, que:

5 Alguns textos aparecerão como cruzamentos ou pontos de ancoragem, tais como tratados do governo descrevendo política. Estes são chamados de textos canônicos ou monumentos.
[...] consideramos que os Estados Unidos não encontrarão melhor parceiro no combate ao terrorismo na medida em que as ações sejam levadas a cabo de forma transparente. Quando as ações são feitas de forma plena fortalecem a confiança. Quando há falta de informação, isso pode enfraquecer a confiança. (OLIVEIRA, 2013)

Já secretário de Estado, descartou qualquer expectativa de os Estados Unidos interromperem a espionagem eletrônica de cidadãos brasileiros, o que demonstrava que havia muito a ser feito para aliviar as tensões consequentes do episódio (OLIVEIRA, 2013).

Em coletiva sobre a espionagem dos EUA, em 2013, com o Ministro da Justiça José Eduardo Cardozo, o então sucessor de Patriota, Ministro Luiz Figueiredo, declarou que a espionagem, mais do que uma violação do direito de privacidade, configurou-se como uma violação da soberania. "[...] isso representa uma violação inadmissível e inaceitável da soberania brasileira [...] Esse tipo de prática é incompatível com a confiança necessária a uma pareceria estratégica entre os dois países" (MENDES, 2013a, p. 1).

Cardozo também relatou que propôs ao vice-presidente dos Estados Unidos, Joe Biden, a adoção de um acordo com o Brasil para regulamentar interceptações telefônicas ou de mensagens trocadas pela internet. Todavia, os americanos recusaram um acordo desse tipo. A proposta era para que interceptações de um país sobre pessoas, autoridades ou empresas de fora só fossem realizadas após autorização judicial do país alvo e somente diante de fortes indícios de irregularidades. "O governo americano disse que não concordava em fazer acordo nesses termos, não só com o Brasil, mas com qualquer país do mundo" (MENDES, 2013b, p. 1). Segundo o ministro, os americanos disseram que só estariam "dispostos a dialogar sobre questões pontuais que pudessem melhorar o entendimento entre Brasil e Estados Unidos" (MENDES, 2013b, p. 1).

Cardozo fez a proposta em razão de os EUA e o Brasil serem países soberanos e parceiros de modo a fixar termos muito claros de respeito a essa relação. "Diante da impossibilidade que tínhamos que buscar um equacionamento bilateral, nós procuraremos os foros internacionais para debater o problema" (MENDES, 2013b, p. 1).

$\mathrm{O}$ ministro Figueiredo, por outro lado, ressaltou a importância de uma mobilização conjunta com países 
parceiros e BRICS ${ }^{6}$ no sentido de tratar o episódio: "Vamos conversar com parceiros, tanto com países desenvolvidos, quanto os BRICS, para avaliar como eles se protegem desse tipo de situação, quais são as ações conjuntas que podem ser tomadas de modo a lidar com um tema grave como esse." (MENDES, 2013b, p. 1).

Já durante cúpula do MERCOSUL no Uruguai, em 2013, a presidente Dilma Rousseff afirmou que o bloco deve adotar medidas cabíveis pertinentes para evitar a repetição de episódios como esse. "Mais do que manifestações, devemos também adotar medidas cabíveis pertinentes para coibir a repetição de situações como essa.” (ROUSSEFF, 2013b, p. 1)

Alvo de agências de espionagem norte-americanas, os governos de Brasil e Alemanha apresentaram ainda à $68^{\mathrm{a}}$ Assembleia Geral da Organização das Nações Unidas (ONU) uma proposta que previa regras para garantir o direito à privacidade na era digital. A proposta "costurada" pelas chancelarias de Brasil e Alemanha recomenda que as Nações Unidas aprovem a adoção de medidas que permitam o fim das violações ao direito à privacidade. Os diplomatas dos dois países também recomendam que todas as nações cumpram as obrigações previstas na legislação internacional de direitos humanos.

As resoluções da Assembleia Geral não são vinculativas, mas carregam significância moral e peso político. A resolução "calls for all countries to guarantee privacy rights to users of the internet and other forms of electronic communications ${ }^{7}$." Ela afirma, ainda, that the same rights that people have offline must also be protected online. [...] expresses concern at the harm that such scrutiny, including spying in foreign states and the mass collection of personal data, may have on human rights ${ }^{8 "}$ (UNITED NATIONS, 2013).

\section{0 papel desempenhado pelos arranjos geopolíticos}

De acordo com Neumann (2008, p. 71),

[...] politics involves contestation between relatively clearly defined positions, which compete to find resonance among a number of carriers. Thus it is desirable to identify these positions. Typically, one position will be dominant, and one or two other positions will challenge it on certain points.

O autor diz, ainda, que "It is important that the discourse analyst start with the representations themselves - the stories of how things have 'always' been like this or that ${ }^{10 "}$ (NEUMANN, 2008, p. 71).

Dessa forma, reconstruir a confiança nas relações bilaterais entre o Brasil e os EUA requer um esforço assertivo, tanto por parte de Brasília quanto por parte de Washington e é algo que poderia acontecer de diversas formas. De acordo com José Luís Fiori, em entrevista à Carta Maior, em 2015, "tem havido um esforço muito grande, de ambas as partes, a favor de uma reaproximação politico-diplomática, e a favor de um aprofundamento das suas relações econômicas, com o estabelecimento de um novo tipo de protocolo na relação entre os dois países" (GALVÃO, 2015).

Ainda de acordo com Fiori, na mesma entrevista,

[...] o importante é ter em conta que as relações entre o Brasil e os EUA estarão sempre condicionadas pelo fato de que: 1) São os dois maiores países do hemisfério ocidental; 2) Os dois foram colonizados pelos europeus e pela sua civilização cristã; 3) Historicamente, o Brasil sempre teve maior dependência dos EUA do que a inversa; 4) Na medida em que o Brasil expanda e projete sua influência internacional, dentro e fora da América do Sul, deverá inevitavelmente competir com os EUA, porque todo país que se propõe ascender a uma nova posição de liderança regional ou global, terá sempre que questionar os arranjos geopolíticos e institucionais que foram definidos e impostos previamente, pelas potencias que já são ou foram dominantes, dentro do sistema mundial. Esta regra, entretanto, nunca impediu nem impedi-

6 Grupo político-econômico constituído por Brasil, Rússia, Índia, China e África do Sul.

7 A resolução apela a todos os países para garantir os direitos de privacidade para usuários de internet e outras formas de comunicações eletrônicas

8 Ela afirma ainda que os mesmos direitos que as pessoas têm off-line também devem ser protegidos online [...] Manifesta preocupação com os danos que tal escrutínio, incluindo a espionagem em Estados estrangeiros e a coleta em massa de dados pessoais, podem ter sobre os direitos humanos.
9 A política envolve contestação entre as posições relativamente bem definidas, que competem para encontrar ressonância entre um número de portadores. Assim, é desejável identificar estas posições. Normalmente, uma posição será dominante, e um ou dois outros cargos irá desafiá-lo em certos pontos.

10 É importante que o analista do discurso apresente representações - as histórias de como as coisas "sempre" foram ou têm sido. 
rá o estabelecimento de convergências e alianças táticas, entre a potência ascendente e uma ou várias das antigas potencias dominantes. (MENDES, 2013b, p.1).

O mais provável é que o Brasil e os EUA se aproximem e distanciem periodicamente, como se fosse numa partida de Weiqi ${ }^{11}$, em que a regra básica é a da coexistência combativa entre os parceiros envolvidos, sem que nunca se chegue à nenhuma espécie de casamento durador, ou, à alguma espécie de xeque-mate definitivo" (MENDES, 2013b, p. 1).

Fiori (2015) ressalta ainda que o Brasil teve um milagre econômico impulsionado pela Guerra Fria e apoio dos EUA, mas que depois do fim da URSS e com a mudança da política internacional americana esse processo foi interrompido - a Alemanha e o Japão teriam presenciado experiência similar. $\mathrm{O}$ autor ressalta que:

O Brasil é muito menos desenvolvido do que a Alemanha e o Japão, mas dispõe de recursos naturais e é autossuficiente do ponto de vista alimentar e energético. Por isso, talvez só o Brasil tenha hoje condições reais de escolher um caminho que lhe dê maior grau de autonomia estratégica, e maior capacidade de projetar seus interesses e sua influência numa escala global (FIORI, 2015, p. 85).

Por outro lado, há quem defenda que o Brasil precisa se inserir no sistema internacional de forma diferenciada, deixando para um segundo plano as atuais características e inovações em política externa, como o MERCOSUL e o BRICS, projetar seus interesses de forma alinhada à política externa dos EUA e em concordância com países que passaram por processos de liberalização econômica, como é o caso do Chile e a sua inserção na Trans-Pacific Partnertship ${ }^{12}$. De acordo com o ex-embaixador dos Brasil nos EUA, Roberto Abdenur, "Devemos preservar o Mercosul, mas ele não pode impedir o Brasil de fazer um esforço tardio de abertura, sobretudo em direção aos países que são fontes de investimento e tecnologia, como os da Europa e os Estados Unidos" (FORNETTI, 2013, p. 1).

11 Jogo estratégico de soma zero para tabuleiro, em que duas pessoas posicionam pedras de cores opostas. Sua origem vem da antiga China, há cerca de 5 mil anos. O jogo é popular no leste da Ásia. Sua tradução significa “jogo de cercar (território)".

12 O Acordo de Parceria Econômica Estratégica Trans-Pacífico (TPSEP, em inglês Trans-Pacific Strategic Economic Partnership Agreement), também referido como P4 (do inglês, $\mathrm{Pa}$ cific 4) é um acordo de livre comércio estabelecido em 2005 entre quarto países da região Ásia-Pacífico: Brunei, Chile, Nova Zelândia e Singapura.
Ainda de acordo com Abdenur,

O MERCOSUL é útil para o país, mas não nos basta. Hoje está acontecendo uma reorganização das forças produtivas pelo mundo. Sem novos acordos comerciais, o Brasil vai ficar de fora das chamadas cadeias produtivas internacionais, a produção fragmentada das multinacionais por vários países. Começa agora a definição do que vai ocorrer no comércio internacional neste século (FORNETTI, 2013).

\section{VII Cúpula das Américas: juntos outra vez}

Nos dias 10 e 11 de abril de 2015, realizou-se a VII Cúpula das Américas. Essa reunião de chefes de Estado do continente, criada no âmbito da Organização dos Estados Americanos (OEA), tratou de diversos assuntos, como "a segurança, a energia, a saúde, a educação, os fluxos migratórios, a governança democrática e a participação dos cidadãos serão os subtemas abordados" (SUMMITS OF THE AMERICAS, 2015).

Entretanto, o que cabe discutir aqui é a oportunidade de reaproximação entre Brasil-EUA, que foi fomentada no âmbito desta cúpula. "Reconhecemos as ações tomadas $[. .$.$] ao longo de vários meses e que levaram$ à posição em que o governo americano disse não só ao Brasil, mas a todo mundo, que os países irmãos e amigos não seriam espionados" (ROUSSEFF, 2015). A julgar pelas declarações da presidente, o episódio parece ter sido parcialmente superado.

Em entrevista coletiva concedida após a reunião bilateral com Obama no âmbito da Cúpula do Panamá, a presidente disse que fará uma visita de trabalho à Washington, e não de Estado. Visitas de Estado são em geral mais longas e exigem o cumprimento de uma série de ritos. A Casa Branca só tinha datas disponíveis para uma visita de Estado no ano de 2016, ano eleitoral tanto no Brasil quanto nos EUA, o que seria inviável. No sentido de reconhecer a importância estratégica do Brasil, Obama declarou que "O Brasil é obviamente não apenas um dos países mais importantes do hemisfério, mas um líder muito importante" (LAMMUCCI, 2015).

$\mathrm{O}$ encontro tratará de temas como mudanças climáticas, educação, cooperação na área de energias renováveis e diversificação do comércio, aumentando os investimentos mútuos e ampliando a cooperação em defesa e aeronáutica. O Brasil deve esperar um esforço proativo por parte de Washington para pôr definitivamente as tensões de lado e reconhecer o país como um parceiro estratégico de grande importância no sistema internacional. 
Nesse sentido, conseguir o apoio de Washington à campanha do Brasil pela reforma do Conselho de Segurança da ONU seria algo tangível, como aponta um especialista do Center for Internacional and Strategic Studies ${ }^{13}$ :

[...] putting those tensions aside is unlikely to be an easy task. Dilma Rousseff will likely expect a proactive effort on the part of Washington-an explicit effort with tangible gestures, aimed at improving bilateral ties, that recognizes Brazil as a key global actor and a high priority for the United States. Supporting Brazil's push for UN Security Council reform could be one potential avenue for demonstrating Washington's appreciation of Brazil's growing global importance (MEACHAM, 2014).

A política exterior brasileira para um assento permanente no Conselho de Segurança da ONU se pauta em uma inserção humanitária no sistema internacional, pacifista e promovedora do respeito ao direito internacional. Dessa forma, a campanha pelo assento pode ser entendida como uma estratégia brasileira para a ampliação de suas áreas de influências, porém sem qualquer intenção de desrespeitar a ordem internacional estabelecida, promovendo maior equilíbrio nas decisões do Conselho tanto quanto ao uso da força, quanto ao equilíbrio regional na América Latina.

Os entraves para a reforma do Conselho de Segurança da ONU, bem como para a campanha do Brasil para tal reforma, vão muito além da questão do apoio de superpotências, como os Estados Unidos. Uma crítica à campanha brasileira seria o caso de o país não ter um hard power equivalente aos outros membros do conselho. Todavia, o Brasil se insere no sistema internacional de forma humanitária e em consonância com o direito internacional, o que poderia representar um maior equilíbrio nas decisões do conselho quanto ao uso da força e questões de intervenção militar.

A forma como o Brasil se insere no sistema internacional, entretanto, não exclui a necessidade de o país desenvolver e investir mais em seu sistema de defesa. Esta necessidade é intrínseca para reafirmar a posição do Brasil não só como potência regional na América do Sul, como também um grande player mundial. Tomamos

13 Think-thank americano com sede em Washington, DC, nos Estados Unidos. O centro realiza estudos políticos e análises estratégicas de questões políticas, econômicas e de segurança em todo o mundo, com um foco específico em questões relativas às relações internacionais, comércio, tecnologia, finanças, energia e geoestratégia. como exemplo a Índia, país emergente, mas que se configura como a quarta potência militar mundial de acordo com o Global Firepower Index ${ }^{14}$ e que também busca um assento permanente no Conselho de Segurança.

\section{Considerações finais}

Através da análise dos discursos das autoridades brasileiras e norte-americanas, analisamos os desdobramentos e consequências da espionagem americana para as relações bilaterais do Brasil com os Estados Unidos, algo que se confirma ao analisar as posições de presidentes, ministros e chefes de Estado em artigos, entrevistas à mídia e discursos em organismos multilaterais.

Em seguida, vimos as questões geopolíticas que o Brasil, como Estado autônomo, está submetido, podendo escolher deixar para um segundo plano suas atuais características de inserção no sistema internacional, como o MERCOSUL e BRICS, abrindo as portas para uma maior liberalização, como aponta um especialista, ou assumir uma posição que lhe afere maior grau de autonomia e competição com os Estados Unidos, como aponta outro especialista.

Por fim, podemos considerar que a visita de Dilma a Washington sinaliza um fim vultoso aos constrangimentos diplomáticos consequentes da espionagem americana. $\mathrm{O}$ encontro, além de reforçar os laços bilaterais, a cooperação em diversos setores e a atualização da agenda bilateral, poderá ser, sim, uma oportunidade de barganha por parte do Brasil à adesão de Washington no que se refere à campanha brasileira por um assento permanente no Conselho de Segurança da ONU.

\section{Referências}

FIORI, José Luís. História, estratégia e desenvolvimento para uma geopolítica do capitalismo. São Paulo: Boitempo, 2015.

FORNETTI, Verena. Só o Mercosul não basta para o Brasil, diz ex-embaixador. 2013. Disponível em: <http:// goo.gl/Mt9uSu>. Acesso em: 03 maio 2015.

GALVÃO, Bruna. José Luís Fiori: Brasil deverá inevitavelmente competir com os EUA. 2015. Disponível em: <http://goo.gl/OyBRO2>. Acesso em: 07 maio 2015.

14 Pesquisa anual que avalia as forças armadas de 160 países e produz um ranking para elencar quais delas são as mais poderosas do mundo. 
HANSEN, Lene. Security as practice: discourse analysis and the Bosnian war. Londres: Routledge, 2006.

LAMMUCCI, Sergio. Dilma vai à Washington em 30 de junho para visita de governo. 2015. Disponível em: $<$ http://goo.gl/U15u28>. Acesso em: 28 abr. 2015.

LUIGI, Ricardo; DAMICO JUNIOR, Nelson. VII Cúpula das Américas e o desafio da cooperação no continente. 2015. Disponível em: <http://mundorama.net/2015/04/08/ vii-cupula-das-americas-e-o-desafio-da-cooperacao-nocontinente-por-ricardo-luigi-e-nelson-damico-junior/>. Acesso em: 05 maio 2015.

MEACHAM, Carl. Does Dilma's reelection mean more of the same for Brazil? 2014. Disponível em: <http://goo.gl/ C0JNn1>. Acesso em: 23 abr. 2015.

MENDES, Pricilla. Violação da soberania brasileira pelos EUA é 'inaceitável', diz governo. 2013a. Disponível em: <http://goo.gl/LqQw9F>. Acesso em: 05 maio 2015.

MENDES, Pricilla; RAMALHO, Renan. Brasil vai discutir espionagem com BRICS e desenvolvidos, diz chanceler. G1. 2013b. Disponível em: <http://goo.gl/a7ER0h>. Acesso em: 05 maio 2015.

NEUMANN, Iver. B. Discourse analysis. In: KLOTZ, Audie; PRAKASH, Deepa (edt.). Qualitative methods in international relations: a pluralist guide department of political science. New York: Palgrave Macmillan, 2008. (Research Methods Series). p. 61-77.

OLIVEIRA, Eliane. Patriota afirma que falta de transparência afeta confiança do Brasil nos EUA. 2013. Disponível em: <http://goo.gl/mabdDM > . Acesso em: 06 maio 2015.
ROUSSEFF, Dilma. Statement by H. E. Dilma Rousseff: President of the Federative Republic of Brazil, at the opening of the General Debate of the 68th Sessions of the United Nation's General Assembly". 2013a. Disponível em: <http://goo.gl/1NWf7f >. Acesso em: 25 abr. 2015.

ROUSSEFF, Dilma. Discurso da Presidenta da República, Dilma Rousseff, durante a reunião de Cúpula dos Estados Parte e Estados Associados do Mercosul e convidados especiais. 2013b. Disponível em: <http://goo.gl/rsDfTN>. Acesso em: 01 maio 2015.

ROUSSEFF, Dilma. Entrevista coletiva concedida pela Presidenta da República Dilma Rousseff, após bilateral com Barack Obama por ocasião da VII Cúpula das Américas - Cidade do Panamá/Panamá. 2015. Disponível em: $<$ http://www2.planalto.gov.br/acompanhe-o-planalto/ entrevistas/entrevistas/entrevista-coletiva-concedidapela-presidenta-da-republica-dilma-rousseff-aposcerimonia-de-encerramento-da-vii-cupula-dasamericas-panama>. Acesso em: 04 maio 2015.

SOARES, Joana. A espionagem norte-americana no Brasil e a hegemonia dos Estados Unidos. 2013. Disponível em: $<$ http://mundorama.net/2013/10/12/a-espionagemnorte-americana-no-brasil-e-a-hegemonia-dos-estadosunidos-por-joana-soares/>. Acesso em: 23 abr. 2015.

SUMMITS OF THE AMERICAS, 7., 2015. Panamá City. Prosperity with equity: the challenge of cooperation in the Americas. Disponível em: <http://goo.gl/3cKhGK>. Acesso em: 20 abr. 2015.

UNITED NATIONS. General Assembly. Resolution adopted by the General Assembly on 18 december 2014. The right to privacy in the digital age. 2015. Disponível em: $\quad<$ http://www.un.org/en/ga/search/view_doc. asp? symbol=A/RES/69/166>. Acessado em: 01 de maio de 2015. 